\title{
Incidence Rate of Dengue Fever in Saudi Arabia 2011-2018, a Retrospective
}

\author{
Tahani Babiker, Gul Mohamed Rasitha Banu, Illham Bashier, M. Hajmeeral
}

\begin{abstract}
Background: Dengue fever is the most unexpectedly spreading mosquito-borne viral disease inside the world. In the last 50 years, incidence rate has accelerated 30-fold with growing geographic expansion to new nations and, in the gift decade from urban to rural settings.

Method: A retrospective cross-sectional study was conducted to assess the magnitude of dengue fever in Saud Arabia. Secondary data was collected from the statistical books from 2011 - 2018, the incidence rate per 100,000 persons was calculated and analyzed.The variables collected included age, sex, nationality and incidence rate distribution by years, month and cities.
\end{abstract}

Results:

The result indicates that the incidence rate of dengue fever was comparatively low in the year 2012 and 2014 than in other years. The number of dengue fever cases started to rise in January, reach its peak between April, May and June. Incidence rate of non-Saudis was greater than that of Saudis, males were more affected than females. Also, the look at indicates that there is an association among occurrence of dengue fever and age distribution.

Conclusion:

Dengue fever cases found in Saudi Arabia during the month of January and the number of cases seems to increase more in the month of April, May and June. It is an endemic in cities like Jeddah, Makah, Medina and Jazan.

Recommendations: Mosquito control programs and effective health education programs regarding prevention and control of dengue fever needed.

\section{INTRODUCTION}

Dengue fever is a serious febrile fever that caused by Aedes allbopictus and Aedes aegypti and mostly in tropical area among the children and adult [1]. Hemorrhagic complications (DHF) or shock (DSS) as well as depression and tiredness are associated with DF symptoms [2] .Over 2.5 billion humans are at risk of contracting dengue worldwide, with an anticipated 390 annual infections (range 284-528 million infections), approximately of which approximately ninety six million had been scientific significant $(24.6 \%)$ [3].It has absolutely been mentioned that as high as $87 \%$ of infections can certainly be clinically irrelevant or in apparent [4] -[5] ,most dengue infections arise in tropical and subtropical areas, as bloodless wintry weather temperatures restriction the distribution of dengue's vectors, and temperature and rainfall have an effect on these mosquitoes' breeding styles and life cycles [6] -[7]. Dengue fever was first discovered in Batavia in 1779 and a year later in Philadelphia,
[8]. 1998, another DF pandemic occurred in 56 countries with an infection of 1.2 million people [9]. In Saudi Arabia, the dengue virus was identified first in Jeddah 1994, on account that that the disease becomes endemic in many towns of Saudi Arabia like Jeddah, Mecca, Medina and Jazan [10].

\section{METHODOLOGY}

This is a cross sectional study was conducted in Saudi Arabia from 2011 to 2018. The data and were collected from statistical book of Ministry of Health. The data included age, sex, nationality and distribution of cases per month and city.

\section{RESULTS}

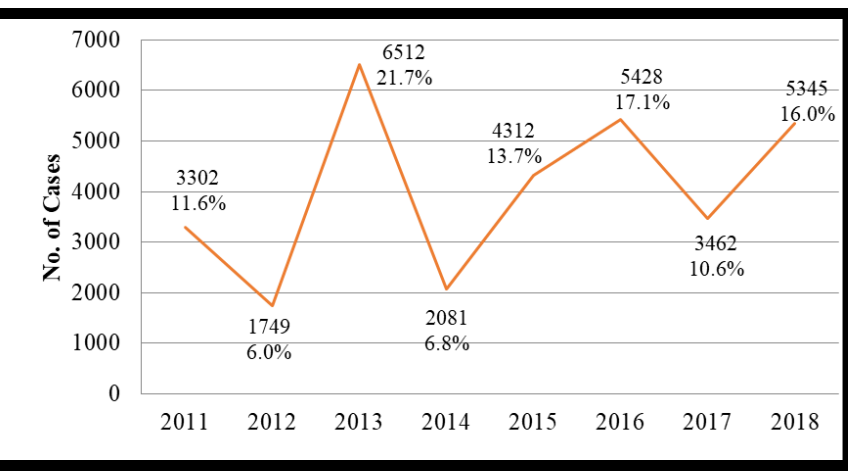

Figure 1: lines shows Incidence Rate of Dengue Fever and Number of Cases in Kingdom of Saudi Arabia, 2011-2018

The result indicates that the Incidence rate for dengue fever per 100,000 persons were higher in the years $2011,2013,2015,2016,2017$ and 2018 was (11.64) (21.71) ( $13.68)(17.1)(10.64)(16.00)$ respectively and was lower in years 2012 and 2014.

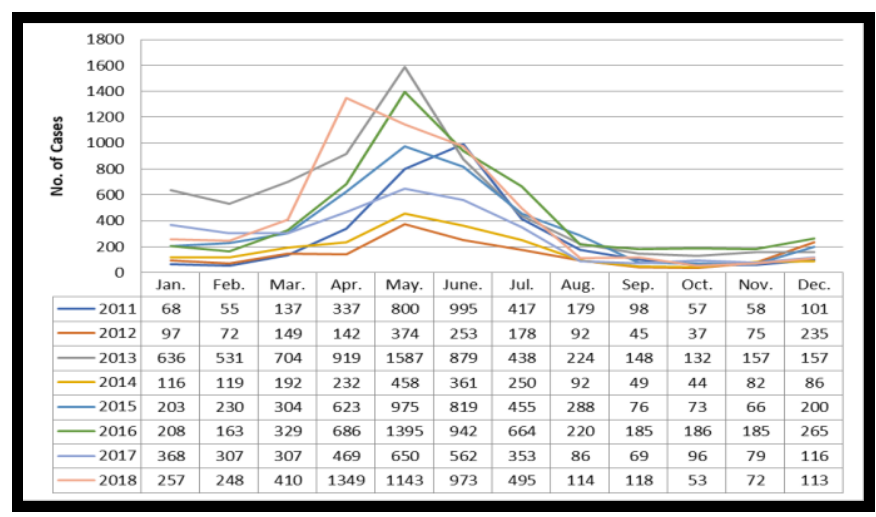

Figure 2: Lines Shows Trends of Dengue Fever by

Months, Kingdom of Saudi Arabia, 2011-2018.

The study revealed that, the majority of cases occurred in April, May and July

Published By:

Blue Eyes Intelligence Engineering 
Table 1: Distribution of dengue fever cases according to the city, Kingdom of Saudi Arabia, 2011-2018

\begin{tabular}{|l|l|l|l|l|l|l|l|l|}
\hline $\mathbf{2 0 1 8}$ & $\mathbf{2 0 1 7}$ & $\mathbf{2 0 1 6}$ & $\mathbf{2 0 1 5}$ & $\mathbf{2 0 1 4}$ & $\mathbf{2 0 1 3}$ & $\mathbf{2 0 1 2}$ & $\mathbf{2 0 1 1}$ & City \\
\hline 0 & 0 & 4 & 0 & 1 & 2 & 1 & 2 & Riyadh \\
\hline 163 & 372 & 450 & 855 & 432 & 1748 & 1580 & 867 & Makkah \\
\hline 4942 & 2656 & 4323 & 3161 & 1524 & 4411 & 0 & 2348 & Jeddah \\
\hline 11 & 6 & 31 & 16 & 7 & 69 & 0 & 25 & Ta if \\
\hline 41 & 105 & 56 & 10 & 31 & 52 & 0 & 0 & Medinah \\
\hline 0 & 0 & 9 & 1 & 0 & 1 & 0 & 0 & Eastern \\
\hline 0 & 0 & 1 & 0 & 0 & 0 & 0 & 0 & Elihsa \\
\hline 0 & 0 & 9 & 0 & 8 & 0 & 0 & 0 & Tabook \\
\hline 174 & 320 & 550 & 266 & 71 & 92 & 165 & 50 & Jazan \\
\hline 14 & 3 & 2 & 3 & 7 & 137 & 3 & 9 & Najran \\
\hline 0 & 0 & 0 & 0 & 0 & 0 & 0 & 1 & El- Bahah \\
\hline 0 & 0 & 2 & 0 & 0 & 0 & 0 & 0 & EIgnphoda \\
\hline 6345 & 3462 & 5428 & 4312 & 2081 & 6512 & 1749 & 3302 & Total \\
\hline
\end{tabular}

\begin{tabular}{|l|l|l|l|l|l|l|l|l|}
\hline City & 2011 & 2012 & 2013 & 2014 & 2015 & 2016 & 2017 & 2018 \\
\hline Riyadh & 2 & 1 & 2 & 1 & 0 & 4 & 0 & 0 \\
& & & & & & & & \\
\hline Makkah & 867 & 1580 & 1748 & 432 & 855 & 450 & 372 & 163 \\
\hline Jeddah & 2348 & 0 & 4411 & 1524 & 3161 & 4323 & 2656 & 4942 \\
\hline Ta if & 25 & 0 & 69 & 7 & 16 & 31 & 6 & 11 \\
\hline Medinah & 0 & 0 & 52 & 31 & 10 & 56 & 105 & 41 \\
\hline Eastern & 0 & 0 & 1 & 0 & 1 & 9 & & 0 \\
\hline Elihsa & 0 & 0 & 0 & 0 & 0 & 1 & 0 & 0 \\
\hline Tabook & 0 & 0 & 0 & 8 & 0 & 9 & & 0 \\
\hline Jazan & 50 & 165 & 92 & 71 & 266 & 550 & 320 & 174 \\
\hline Najran & 9 & 3 & 137 & 7 & 3 & 2 & 3 & 14 \\
\hline El- Bahah & 1 & 0 & 0 & 0 & 0 & 0 & & 0 \\
\hline Elgnphoda & 0 & 0 & 0 & 0 & 0 & 2 & 0 & 0 \\
\hline Total & 3302 & 1749 & 6512 & 2081 & 4312 & 5428 & 3462 & 6345 \\
\hline
\end{tabular}

High Incidence rate of dengue fever reported from four cities Jeddah, Makkah, Madinah and Jazan.

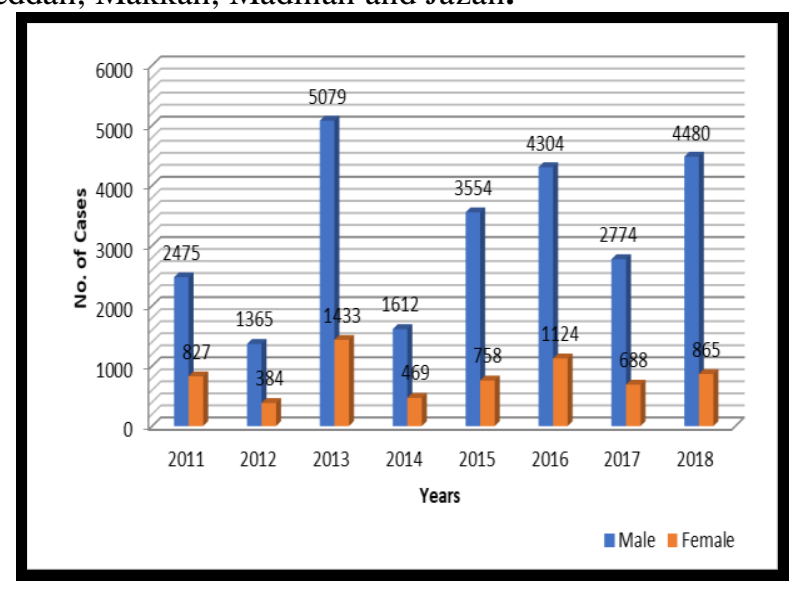

Figure 4: Bars Shows Number of Males and Females Contracted Dengue in Kingdom of Saudi Arabia, 2011-2015.

From the statistical book, the reports showed that the male were at significant risk of acquiring the dengue fever infection comparing to female.

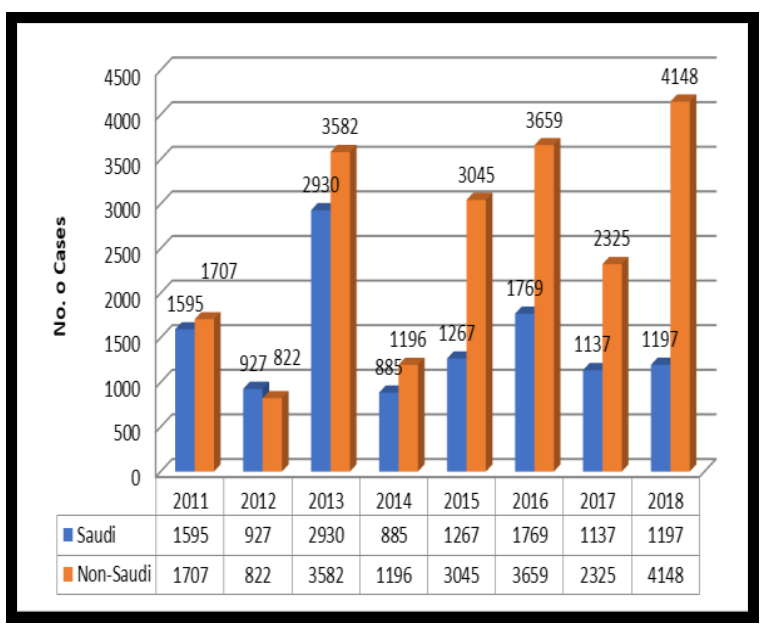

Figure 5: Bars Shows Number of Saudian and Non-Saudian Contracted Dengue Fever, Kingdom of Saudi Arabia, 2011-2015.

Most cases were found high among Non- Saudi than Saudi person. 
Table 2: Association between Incidence rate of dengue fever and age group, Kingdom of Saudi Arabia, 2011-2018.

\begin{tabular}{|c|c|c|c|c|}
\hline Age & $\begin{array}{c}\mathbf{2 0 1 1 -} \\
\mathbf{2 0 1 2}\end{array}$ & $\begin{array}{c}\mathbf{2 0 1 3 -} \\
\mathbf{2 0 1 4}\end{array}$ & $\begin{array}{c}\mathbf{2 0 1 5} \\
\mathbf{2 0 1 6}\end{array}$ & $\begin{array}{c}\mathbf{2 0 1 7 -} \\
\mathbf{2 0 1 8}\end{array}$ \\
\hline $\begin{array}{c}1-5 \\
\text { years }\end{array}$ & 143 & 128 & 460 & 176 \\
\hline $\begin{array}{c}5-15 y \\
\text { ears }\end{array}$ & 451 & 676 & 569 & 525 \\
\hline $\begin{array}{c}15--4 \\
5 y e a r s\end{array}$ & 900 & 1688 & 5734 & 8106 \\
\hline
\end{tabular}

The study revealed that there is an association between the incidence rate of dengue fever and age group.

\section{DISCUSSION}

Dengue Fever (DF) maintains to be a first-rate public health trouble within the country. Many risk factors make KSA prone to outbreaks and epidemics; amongst these, Increased tour among humans to neighboring States for the motive of jobs and trades is probably answerable for the spread of the disease, fast unplanned urbanization with heavy construction activities and bad sanitation facilities make contributions to fertile breeding grounds for the mosquitoes, possibility of resistance of Ae. Aegypti to the insecticides have been reported in the distinctive elements of Jazan (AL sheikh et al. 2016). Also, the poor know-how about the hobby of mosquito main to poorer protective practices in opposition to the mosquito. (Elyas et al, 2016).

The study reported that maximum number of dengue cases seen in April, May and June, which indicated an active viral transmission during this period. Most studies in the review found that dengue transmission is highly sensitive to climatic conditions, especially temperature, rainfalls and relative humidity (Horta 2014).

The disease is endemic in many elements of KSA, with the majority of cases concentrated in four towns (Jeddah, Makah, Madinah and Jizan). These cities are the websites of both the yearly pilgrimage (Hajj) and the minor pilgrimage (Umrah), which might be completed by almost three million Muslims from everywhere in the world. Second, even more visitors come to Jeddah for the duration of the summertime. Third, those pilgrimages arise for the duration of the rainy season. Fourth, greater humidity and excessive temperatures may assist exacerbate the situation, making Makah and Jeddah extra liable to infectious diseases (Khormi 2012) (Khan 2008). Some sporadic instances in Jizan have been defined as because of the nature of the city; Jizan is notably flat and placed at sea level; hence, the probability of the formation of small stagnant water collections is excessive following the rainfall (Al-Azraqi 2013 ). Another examines in Brazil also showed that the risk of dengue transmission improved with excessive temperatures. The study revealed that male were at significant risk of acquiring the dengue fever infection comparing to female ,these findings are consistent with studies have shown that male and young age are significant risk factors for DF (Alzahrani 2013) (Ayub 2006).

\section{REFERENCES}

1. Lambrechts, L., Scott, T.W. andGubler, D.J., C o n s e qu e n c e s of the expanding g lobal distribution of Aedes albopictus for dengue virus transmission. PLoSNegl Trop Dis. 2010; 4:1-9.

2. Gubler, D.J., Dengue/dengue hemorrhagic fever: history and status. Novartis Found Symp. 2006; 277:3-16.

3. Bhatt, S., Gething, P. W., Brady, O. J., Messina, J. P., Farlow, A. W., Moyes, C. L., \& Myers, M. F. (2013). The global distribution and burden of dengue. Nature, 496(7446), 504

4. Burke, D. S., Nisalak, A., Johnson, D. E., \& Scott, R. M. (1988). A prospective study of dengue infections in Bangkok. The American journal of tropical medicine and hygiene, 38(1), 172-180.

5. Thai, K. T., \& Anders, K. L. (2011). The role of climate variability and change in the transmission dynamics and geographic distribution of dengue. Experimental Biology and Medicine, 236(8), 944-954.

6. Delatte, H., Gimonneau, G., Triboire, A., \& Fontenille, D. (2009) Influence of temperature on immature development, survival, longevity, fecundity, and gonotrophic cycles of Aedes albopictus, vector of chikungunya and dengue in the Indian Ocean. Journal of medical entomology, 46(1), 33-41.

7. Morin, C. W., Comrie, A. C., \& Ernst, K. (2013). Climate and dengue transmission: evidence and implications. Environmental health perspectives, 121(11-12), 1264.

8. World Health Organization. Asia-Pacific dengue program managers meeting. Manila Western Pacific Region; 2008.

9. Libraty, D.H., Young, P.R., Pickering, D., et al. High circulating levels of the dengue virus nonstructural protein NS1 early in dengue illness correlate with the development of dengue hemorrhagic fever. J. Infect. Dis., 2002; 186: 1165-1168.

10. M. Fakeeh, A.M. ZakiVirologic and serologic surveillance for dengue fever in Jeddah, Saudi Arabia, 1994-1999 Am J Trop Med Hyg, 65 (2001), pp. 764-767

11. Ministry of Health, Department of Statistics Health statistical year book 2009 Saudi Ministry of Health, Riyadh, KSA (2010) ISSN: 1319-3228

12. AL sheikh, A. A., Mohammed, W. S., Noureldin, E. M., Daffalla, O. M., Shrwani, K. J., Hobani, Y. A., \& Binsaeed, A. A. (2016). Resistance status of Aedes aegypti to insecticides in the Jazan Region of Saudi Arabia. Biosciences Biotechnology Research Asia, 13(1), 155.

13. ELyas, Tahani B, ELsidig, Ebtihag M, Aseri, Abrar, Break, Awsaf, Salim, Halima, Adil, Rania, \& Hamoud, Rafef. (2016). Knowledge, Attitudes and Preventive Practices of House Hold Regarding Dengue Fever in the Rural Areas of Jazan Region, Saudi Arabia. International Journal of Preventive Medicine Research, 2(2), 8-12.

14. Horta MA, Bruniera R, Ker F, Catita C, Ferreira AP. Temporal relationship between environmental factors and the occurrence of dengue fever. Int J Environ Health Res 2014:1-11.

15. Khormi, H. M., \& Kumar, L. (2012). Assessing the risk for dengue fever based on socioeconomic and environmental variables in a geographical information system environment. Geospatial health, 6(2), 171-176.

16. Khormi, H. M., \& Kumar, L. (2012). The importance of appropriate temporal and spatial scales for dengue fever control and management. Science of the total environment, 430, 144-149.

17. Khan, N. A., Azhar, E. I., El-Fiky, S., Madani, H. H., Abuljadial, M. A., Ashshi, A. M. \& Hamouh, E. A. (2008). Clinical profile and outcome of hospitalized patients during first outbreak of dengue in Makah, Saudi Arabia. Acta tropica, 105(1), 39-44.

18. Al-Azraqi, T. A., El Mekki, A. A., \& Mahfouz, A. A. (2013). Seroprevalence of dengue virus infection in Aseer and Jizan regions, Southwestern Saudi Arabia. Transactions of the Royal Society of Tropical Medicine and Hygiene, 107(6), 368-371.

19. Alzahrani, A. G., Al Mazroa, M. A., Alrabeah, A. M., Ibrahim, A. M., Mokdad, A. H., \& Memish, Z. A. (2012). Geographical distribution and spatio-temporal patterns of dengue cases in Jeddah Governorate from 2006-2008. Transactions of the Royal Society of Tropical Medicine and Hygiene, 107(1), 23-29.

20. Ayyub, M., Khazindar, A. M., Lubbad, E. H., Barlas, S., Alfi, A. Y., \& Al-Ukayli, S. (2006). Characteristics of dengue fever in a large public hospital, Jeddah, Saudi Arabia. J Ayub Med Coll Abbottabad, 18(2), 9-13. 